\title{
IT WAS A SUPRACLINOID STENOSIS RATHER THAN EXTRACRANIAL CAROTID STENOSIS
}

\author{
CHOWDHURY RN ${ }^{1}$, RAHMAN KM ${ }^{2}, \mathrm{KHAN} \mathrm{SU}^{3}$, SARKER RN ${ }^{4}$, NABI S ${ }^{5}$, SIDDIQUI MR ${ }^{6}$, \\ MOHAMMAD QD ${ }^{7}$
}

\begin{abstract}
:
Carotid stenosis, both intracranial and extracranial is a significant risk factor for transient ischaemic attack and ischaemic stroke. Significant carotid stenosis increases the risk of artery to artery embolization. Duplex Ultrasound (USD) is a screening test for identification and grading of carotid stenosis. USD is less sensitive and specific than cerebral Digital Subtraction Angiogram (DSA) for evaluation of carotid stenosis. USD might underestimate or overestimate degree of carotid stenosis. Here a case is presented where USD found bilateral significant extracranial carotid stenosis, whereas DSA reported no right common carotid artery and left common carotid artery bifurcation stenosis rather there was significant $70 \%$ supraclinoid right internal carotid artery stenosis.
\end{abstract}

Key words: Carotid stenosis, Supraclinoid stenosis, Duplex ultrasound examination, Digital subtraction angiogram

J Dhaka Med Coll. 2011; 20(1): 75-77.

\section{Introduction:}

Stroke is the leading cause of disability worldwide and ranks third among the leading causes of death around the world. Carotid artery disease (both extracranial and intracranial) is responsible for one third of all ischemic strokes. ${ }^{1}$ Therefore, the management of carotid artery disease is undergoing thorough scientific evaluation. Ability to accurately assess the degree of stenosis has become important with studies like ACAS (Asymptomatic Carotid Atherosclerosis Study), NASCET (North American Symptomatic Carotid Endarterectomy) and ECST (European Carotid Surgery Trial). 2,3,4 There are different investigations like Doppler ultrasound, MR angiogram, CT angiogram and DSA for detecting and grading carotid stenosis.

\section{Case report:}

A 70 years old man known hypertensive and diabetic admitted to Department of Neurology of Dhaka Medical College Hospital on 01 July, 2008. He had a history of sudden development of Right sided weakness and slurring of speech persisting for the last 2 months. This episode was not associated with loss of consciousness, fever or any other neurological complaint. He had one episode of TIA before this attack. On examination, his pulse was $82 / \mathrm{min}$, regular, BP $150 / 90 \mathrm{~mm}$ of mercury, carotid bruit was absent. Neurological examination revealed motor dysphasia, right sided upper motor neuron type of facial palsy and GCS was 14 . He had right hemiparesis with grade 4 weakness. He was not catheterized and could take oral feed. He had good functional recovery, and could perform his day to day activity with some

1. Dr. Rajib Nayan Chowdhury, Assistant Professor, Department of Neurology, Dhaka Medical College, Dhaka.

2. Dr. Kazi Mohibur Rahman, Assistant Professor, Department of Neurology, Dhaka Medical College, Dhaka.

3. Dr. Sharif Uddin Khan, Assistant Professor, Department of Neurology, Dhaka Medical College, Dhaka.

4. Dr. Robindranath Sarker, Assistant Professor, Department of Radiology \& Imaging, Dhaka Medical College, Dhaka.

5. Dr. Shahryar Nabi, Assistant Professor, Department of Radiology \& Imaging, Dhaka Medical College, Dhaka.

6. Dr. Mahmudur Rahman Siddiqui, FCPS (Medicine) Course, Dhaka Medical College, Dhaka.

7. Prof. Quazi Deen Mohammad, Head, Department of Neurology \& Principal, Dhaka Medical College, Dhaka.

Address of correspondence: Dr. Rajib Nayan Chowdhury, Assistant Professor, Department of Neurology, Dhaka Medical College, Dhaka. Email: rajibchow86@yahoo.com 


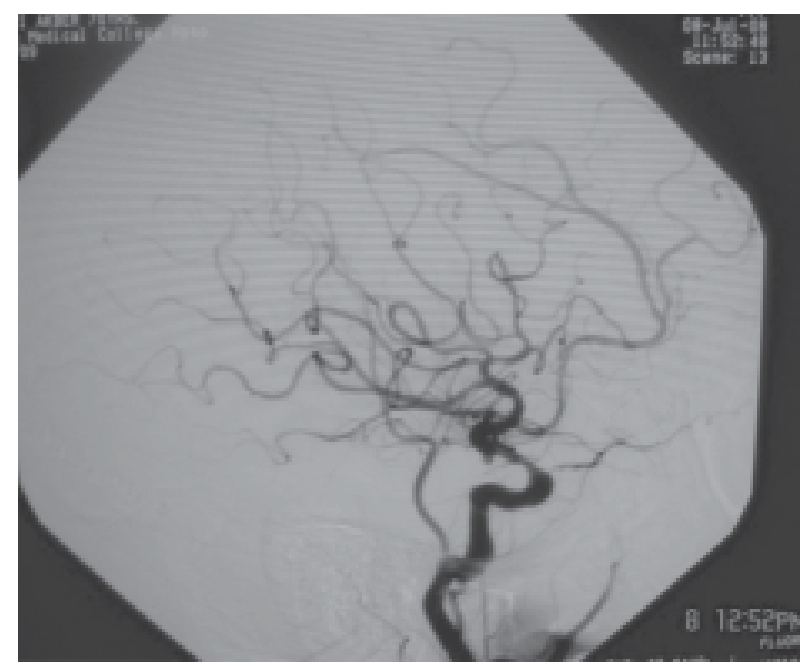

Fig. 1: The arrow shows $70 \%$ right supraclinoid internal carotid artery stenosis in a cerebral digital subtraction angiogram of the patient.

assistance. Investigation: FBS $6.3 \mathrm{mmol} / 1$, $2 \mathrm{ABF} 9.3 \mathrm{mmol} / 1$, S. creatinine $1.2 \mathrm{mg} / 1$ and lipid profile was normal. CT scan of Brain revealed left sided cerebral infarct. Duplex study of carotid revealed $51-53 \%$ stenosis at LICA (left internal carotid artery) and $50-62 \%$ stenosis at RICA (Right internal carotid artery). He was admitted in Neurology Department and cerebral DSA (Digital Subtraction Angiogram) was planned for further evaluation. Cerebral DSA was done through Right Femoral Artery approach under L/A. Selective angiogram was done on RCCA, LCCA \& RVA (Right Vertebral Artery) \& DSA were performed in different planes. RCCA angiogram reveals no bifurcation stenotic disease but there was 70\% Right supraclinoid ICA (Internal Carotid Artery) stenosis. Right PCOM (Posterior Communicating Artery) was hypoplastic. RVA is dominant and angiogram reveals $50 \%$ osteal stenosis. LCCA angiogram reveals no bifurcation stenotic disease. On LCCA angiogram after Right carotid compression there is filling of MCA territory through patent ACOM (Anterior Communicating Artery). Impression: $70 \%$ Right supraclinoid ICA stenosis and RVA 50\% osteal stenosis. Procedure was uneventful and patient was discharged on $3^{\text {rd }}$ day with antihypertensive, antiplatelet, antidiabetic and lipid lowering agent. To prevent further ischemic stroke patient was adviced to do endovascular intracranial \& vertebral stenting.

\section{Discussion:}

Carotid endarterectomy has been proven to be more beneficial than medical therapy in symptomatic patients with greater than $70 \%$ stenosis. Carotid endarterectomy produces a reduction in ipsilateral stroke in asymptomatic patients with greater than $60 \%$ stenosis. ${ }^{5,6}$ On the basis of these results, patients with either symptomatic stenosis $50 \%$ or asymptomatic stenosis $60 \%$ are presently considered for carotid recanalization. Carotid recanalization can be done by endarterectomy or stenting. Before doing any of the above procedures, diagnosis of site, size and severity of carotid stenosis should be confirmed. Duplex sonography, combining high-resolution imaging and Doppler spectrum analysis has proved to be popular, non invasive and cost effective means of detecting and assessing carotid disease. ${ }^{7}$ But USD is less sensitive and specific than DSA for grading of carotid stenosis. DSA is gold standard for carotid artery disease in demonstrating lesion, and provide dynamic view of extracranial \& intracranial carotid stenosis, although it is invasive, costly and uses radio contrast dye. ${ }^{8,9}$

\section{Conclusion:}

USD underestimates or overestimates degree of carotid stenosis and might miss a significant intracranial carotid stenosis. So to avoid inappropriate intervention the form of carotid endarterectomy or carotid artery stenting, it would be wise to do Digital Subtraction Angiogram of the carotid vessels.

\section{References:}

1. Boon NA, Colledge NR. Walker BR, Hunter JAA, eds. Cerebrovascular disease, Davidson's principles and practice of Medicine. 20 ${ }^{\text {th }}$ ed. Edinburgh: Churchil Liningstone; 2006. p.1200-10.

2. Clinical advisory: Carotid endarterectomy for patients with asymptomatic internal carotid stenosis. Stroke 1994; 25: 2523-4.

3. North American symptomatic carotid endarteroctomy trial (NASCET) collaborators. Beneficial effect of carotid endarterectomy in symptomatic patients with high-grade stenosis. New Engl J Med 1991; 223: 445-53. 
4. European Carotid Surgery Trialists (ECST) Collaborative Group MRC European Carotid surgery trial-interim results for symptomatic patients with severe (70\%-90\%) and mild (0\%-29\%) carotid stenosis. Lancet 1991; 337: 1235-43.

5. Rothwell PM, Gibson R, Warlow CP. Interrelation between plaque surface morphology and degree of stenosis on carotid angiograms and the risk of ischemic stroke in patients with symptomatic carotid stenosis. Stroke 2000; 31: 615-21.

6. Executive committee for the asymptomatic carotid atherosclerosis study. JAMA 1995; 273: 1421-8.

7. Bluth E, Stavors A, Marik A. Carotid duplex sonography: a multicentre recommendation for standardized imaging and doppler. Oriteria Radiographics 1998; 21: 487-506.

8. Chowdhury RN, Rahman KM, Khan SU, Sarker RN, Nabi S, Siddiqui MR, et al. Digital Subtraction Angiogram (DSA) is superior to Duplex Ultrasound (USD) in diagnosis of extracranial carotid stenosis - a comparative study. J Medicine 2011; 12: $12-16$

9. Hideki O, Kei T, Hiroya $\mathrm{R}$ Masahiro T, Takayuki $\mathrm{Y}$, Akihiro S, et al. Quantitative vascular measurements in arterial occlusive disease. Radiographics 2005; 25: 1141-58. 